SHORT REPORT

\title{
Mitochondrial DNA haplotyping revealed the presence of mixed up benign and neoplastic tissue sections from two individuals on the same prostatic biopsy slide
}

\author{
A Alonso, C Alves, M P Suárez-Mier, C Albarrán, L Pereira, L Fernández de Simón, P Martín, \\ O García, L Gusmão, M Sancho, A Amorim
}

DNA typing was requested to investigate a presumptive cancer diagnosis error by confirming whether benign and cancerous prostatic tissue in the same presurgical haematoxylin and eosin stained slide belonged to the same person. After independent histological re-examination of the slide by a pathologist, manual slide dissection was used to guarantee independent and high recovery DNA isolation from each tissue section, avoiding carryover and background contamination. Nuclear DNA quantification performed by real time polymerase chain reaction (PCR) revealed the absence of human DNA for short tandem repeat (STR) typing. Mitochondrial DNA was only obtained by performing PCR of very short fragments ( 100 bp), indicating high DNA degradation. Different low frequency hypervariable region I haplotypes were obtained from each tissue section (normal tissue section haplotype: 16224C, 16234T, 16311C, 16356C; cancer tissue section haplotype: 16256T, 16270T, 16293G). Only the normal tissue section haplotype matched that obtained from the patient's blood sample, indicating that the cancer tissue section originated from an unknown patient. These results supported the hypothesis of sample mix up during block processing or slide preparation by a carryover mechanism. Mitochondrial genetic typing is recommended to exclude the possibility of carryover artefacts when low DNA content and high degradation compromise conventional STR typing.
$\mathrm{T}$ ssue specimen mix ups are a challenging problem in surgical pathology practice. ${ }^{1}$ Tissue carryover artefacts leading to mix ups can be produced during gross dissection of specimens or in the preparation of paraffin wax embedded tissue blocks, ${ }^{2}$ or even during the cutting of tissue sections and the preparation of microscope slides. Tissue mix ups are extremely serious when the benign tissue of a patient is contaminated by the cancerous tissue of another patient, leading to unnecessary major surgery. Various DNA typing methods have been described to identify and sort out mixed up tissue specimens, including different microsatellite markers, ${ }^{2-4}$ other nuclear DNA markers, ${ }^{5}$ or even mitochondrial DNA (mtDNA) sequence polymorphisms. ${ }^{3}$

"We recommend mitochondrial DNA haplotyping of short polymerase chain reaction amplicons as an alternative to conventional short tandem repeat typing of archival specimens with low DNA content and high DNA degradation"
Here, we present an unusual case of a suspected tissue mix up that required independent genetic analysis of different presurgical tissue sections on the same slide to confirm whether or not the benign and neoplastic prostatic tissues came from a patient who was diagnosed with prostatic adenocarcinoma and submitted to radical prostatectomy. We describe a simple protocol for independent and high DNA recovery from each tissue section, followed by a sensitive real time polymerase chain reaction (PCR) method to evaluate the presence of nuclear DNA for microsatellite typing. The use of a special mtDNA PCR typing method, which uses primers to generate very short amplicons (approximately $100 \mathrm{bp}){ }^{6}$ was the only strategy that succeeded in establishing the maternal lineage of the cancer and normal tissue sections, demonstrating the presence of a tissue mix up. Therefore, we recommend mtDNA haplotyping of short PCR amplicons as an alternative to conventional short tandem repeat (STR) typing of archival specimens with low DNA content and high DNA degradation.

\section{MATERIALS AND METHODS Samples \\ The following samples were received for analysis:}

- The presurgical haematoxylin and eosin stained slide specimen in question, which contained six tissue sections (numbered from TS1 to TS6) (fig 1).

- A reference bloodstain card sample from the presumptive patient.

Histological examination and photo documentation The slide was studied microscopically for pathological diagnoses taking a series of photographs of all the fragments.

\section{Slide preparation for DNA extraction}

All the following steps were carried out in a laminar flow cabinet located in a dedicated pre-PCR laboratory separated from the post-PCR laboratory and from another pre-PCR laboratory where the reference sample extractions and amplifications were set up. Ultraviolet irradiation and treatment with $10 \%$ bleach were used to eliminate possible DNA contaminants from cabinets and laboratory surfaces.

Before cover slip removal the slide was submitted to different washing steps (first with $50 \mathrm{ml}$ of a sterile $0.1 \%$ sodium dodecyl sulfate solution, followed by two washes with sterile and distilled water and finally with ethanol to

Abbreviations: $A M G$, Amelogenin gene; $\mathrm{HVI}$, hypervariable region I; LCN, low copy number; mtDNA, mitochondrial DNA; PCR, polymerase chain reaction; STR, short tandem repeat; TS, tissue section 
A

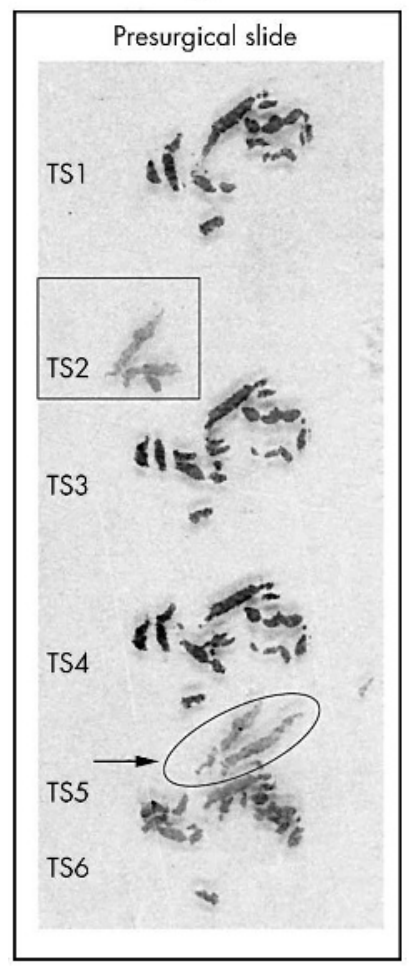

B

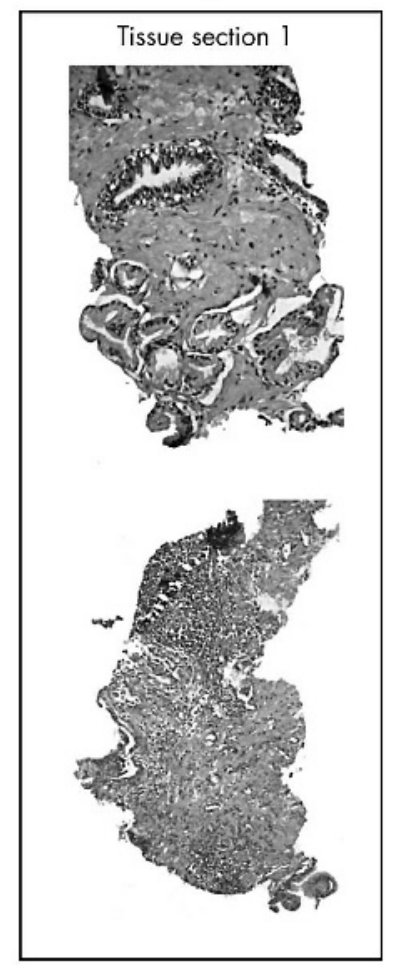

C

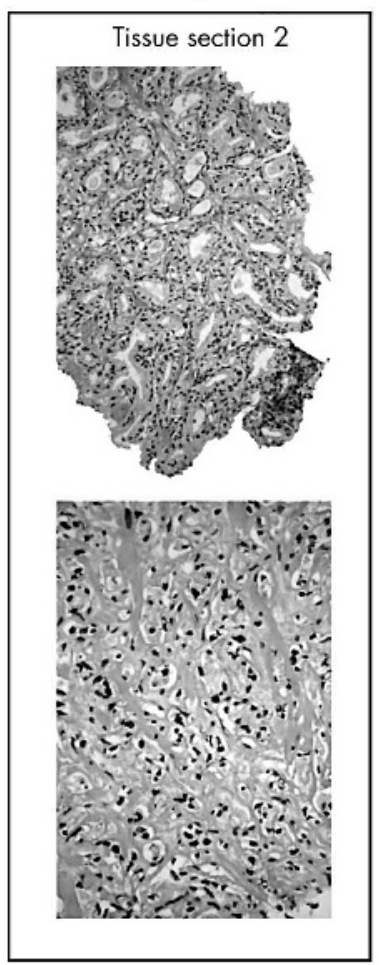

Figure 1 Macroscopic view of the presurgical slide and some microscopic details of the benign and tumour tissue sections that were submitted to DNA isolation. (A) Haematoxylin and eosin stained slide showing six different tissue sections, including a group of four prostate benign tissue sections (TS1, TS3, TS4, and TS6) and a group of two prostate tumour tissue sections (TS2 and TS5). (B) Tissue section 1. Upper panel: benign glands admixed with pancreatic stroma (original magnification, $\times 20$ ); lower panel: prominent lymphocytic inflammation (original magnification, $\times 10)$ ) (C) Tissue section 2. Upper panel: tumour consisting of uniform, single, separate, closely packed glands (original magnification, $\times 20$ ); lower panel: cords of tumorous cells (original magnification, $\times 40$ ).

remove remaining indelible ink labels) to eliminate external DNA contamination.

The cover slip was removed after immersion in xylene for 18 hours in a sterile Petri dish. The slide (without the cover slip) was immersed again in xylene for five minutes to remove the fixation medium completely, thereby assuring complete tissue accessibility during the subsequent proteinase K digestion and DNA purifications steps.

The slide was then cut with a diamond cutter (previously treated with ultraviolet light) to obtain two portions of the glass slide, one containing tissue section 1 (TS1) and the other tissue section 2 (TS2) (fig 1). Each tissue section was introduced into a sterile $15 \mathrm{ml}$ tube for DNA extraction.

\section{DNA extraction}

DNA was extracted from each tissue section by overnight proteolytic digestion at $56^{\circ} \mathrm{C}$ with $2 \mathrm{ml}$ of $0.2 \mathrm{M}$ sodium acetate buffer ( $\mathrm{pH} 8$ ) containing $0.8 \mathrm{mg}$ of proteinase $\mathrm{K}, 0.5 \%$ of sodium dodecyl sulfate and $0.04 \mathrm{M}$ dithiothreitol. The mixture was then extracted once with phenol/chloroform/ isoamyl alcohol (25/24/1). The aqueous phase was washed three times with $2 \mathrm{ml}$ of $10 \mathrm{mM}$ TE buffer using Centricon100 centrifugal devices (Millipore). DNA extracts were concentrated to $40 \mu \mathrm{l}$.

\section{Measurement of DNA}

Human nuclear DNA was measured by slot blot hybridisation with the primate specific Dl7Z1 $\alpha$ satellite probe ${ }^{7}$ using Quantiblot (Applied Biosystems, Foster City, California, USA), and also by a real time PCR to target a segment of the $\mathrm{X}-\mathrm{Y}$ homologous Amelogenin (AMG) gene, which allowed the simultaneous estimation of a Y specific fragment
(AMGY: $112 \mathrm{bp}$ ) and an X specific fragment (AMGX: $106 \mathrm{bp}$ ) using the primers, fluorogenic probes, and PCR conditions described previously, ${ }^{8}$ but instead of using the $1 \times$ TaqMan Universal PCR Master Mix (Applied Biosystems) we used the GeneAmp PCR buffer from Applied Biosystems (10x: $500 \mathrm{mM} \mathrm{KCl}, 100 \mathrm{mM}$ Tris/HCl (pH 8.3), $15 \mathrm{mM} \mathrm{MgCl}_{2}$, and $0.01 \%$ (wt/vol) gelatine), supplemented with $200 \mu \mathrm{M}$ dNTPs, $2.5 \mathrm{U}$ AmpliTaq Gold DNA polymerase, $0.5 \mu \mathrm{M}$ ROX reference dye (Invitrogen, Carlsbad, California, USA), and $50 \mathrm{ng} / \mu \mathrm{l}$ of bovine serum albumin (Sigma, Poole, Dorset, UK).

The measurement of human mtDNA was performed by monitoring the real time progress of the PCR amplification of two different fragment sizes ( $113 \mathrm{bp}$ and $287 \mathrm{bp}$ ) within the hypervariable region I (HVI) of the mtDNA control region, using two fluorogenic probes to determine the mtDNA copy of each fragment size category. ${ }^{8}$

Real time PCR reactions were run and analysed using an ABI PRISM 7000 Sequence Detection System (Applied Biosystems).

\section{Mitochondrial DNA sequence analysis}

Analysis of mtDNA from the blood reference sample was performed by amplifying the entire HVI in a single PCR reaction using the primers and PCR conditions described previously. ${ }^{9}{ }^{10}$

The DNA isolated from the slide tissue sections TS1 and TS2 was analysed by two multiplex PCR hot start reactions (using AmpliTaq Gold DNA polymerase from Applied Biosystems) of non-overlapping short fragments (100$130 \mathrm{bp}$ ) to cover the whole of HVI. ${ }^{6}$ Multiplex I included three primer pairs: (1) forward primer Ll5978 (Al) CACCATTAGCACCCAAAGCT, and reverse primer H16090 


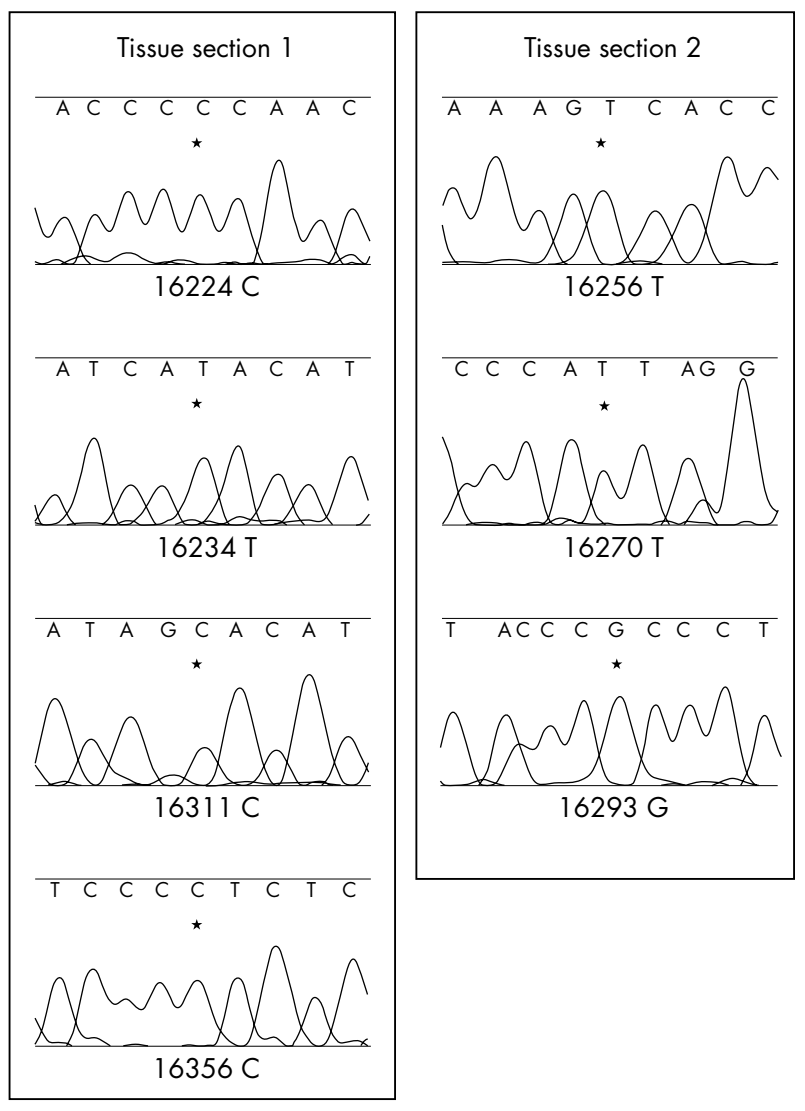

Figure 2 Mitochondrial DNA sequence data from tissue sections TS1 and TS2, including all the nucleotide differences (marked by asterisks in the electropherograms) with the Cambridge Reference Sequence ${ }^{16}$ after alignment and comparison with the entire hypervariable region I sequence data (16024-16365) edited from each tissue section.

(AlR) ACATAGCGGTTGTTGATGGG; (2) forward primer L16112 (2F) CACCATGAATATTGTACGGT, and reverse primer H16237 (2R) TGTGTGATAGTTGAGGGTTG; and (3) forward primer L16268 (4F) CACTAGGATACCAACAAACC, and reverse primer H16398 (4R) CAAGGGACCCCTATCT GAGG. Multiplex II included two primer pairs: (1) forward primer L16036 (1F) GAAGCAGATTTGGGTACCAC, and reverse primer H16159 (IR) GTACTACAGGTGGTCAAGTAT; and (2) forward primer L16190 (3F) CCCCATGCTTACAAG CAAGT, and reverse primer Hl6322 (3R) TGGCTTTATGT ACTATGTAC. PCR conditions for multiplex I were 10 minutes at $95^{\circ} \mathrm{C}$, followed by 36 cycles of $95^{\circ} \mathrm{C}$ for 10 seconds, $60^{\circ} \mathrm{C}$ for 30 seconds, and $72^{\circ} \mathrm{C}$ for 30 seconds, with a final extension of 10 minutes at $72^{\circ} \mathrm{C}$. PCR conditions for multiplex II were 10 minutes at $95^{\circ} \mathrm{C}$, followed by 36 cycles of $95^{\circ} \mathrm{C}$ for 10 seconds, $58^{\circ} \mathrm{C}$ for 30 seconds, and $72^{\circ} \mathrm{C}$ for 30 seconds, with a final extension of 10 minutes at $72^{\circ} \mathrm{C}$.

In both cases, the purified PCR products were sequenced using the ABI-PRISM d-rhodamine cycle sequencing ready reaction kit (Applied Biosystems). The sequencing products were analysed on an ABI377 DNA sequencer.

\section{RESULTS AND DISCUSSION}

The first limitation to DNA typing in our present case was the low amount of DNA that could be isolated from each tissue section. A high degree of DNA degradation could also be expected because of the effect of formalin fixation and the possible oxidation of the DNA molecules during storage at ambient temperature for five years. Therefore, each tissue section was treated as a potential low copy number (LCN)
DNA sample. ${ }^{11}{ }^{12}$ Consequently, we used a protocol that would minimise background DNA contamination and ensure optimal use of the limited amounts of DNA found in each tissue section, thereby avoiding unnecessary waste of DNA. Histological re-examination by an independent pathologist and macro and micro photo documentation were also mandatory steps of the protocol because of the destructive nature of the DNA extraction procedure.

A macroscopical examination of the haematoxylin and eosin stained slide allowed us to identify six different tissue sections numbered from TS1 to TS6 (fig 1). With the naked eye we identified four similar sections (TS1, TS3, TS4, and TS6) formed by a series of fragments and two other sections (TS2 and TS5), which were similar to one another, formed by two main fragments. Microscopically, in TS1, TS3, TS4, and TS6, we identified needle biopsy benign prostatic tissue with focal chronic prostatitis (fig 1B), but without neoplastic tissue. In both of the main fragments of TS2 and TS5, groups of neoplastic glands were seen. In some areas (fig lC, upper panel) tumorous cells formed single, separate, uniform glands in closely packed masses with irregular limits (Gleason pattern 2), ${ }^{13}$ whereas in others (fig 1C, lower panel), tumorous cells formed small glands or infiltrating cords without luminal differentiation (Gleason pattern 3-4). Under high power, some nuclei were enlarged with occasional nucleoli.

DNA was extracted independently from tissue sections TS1 and TS2 after a simple manual glass slide cutting procedure using a diamond cutter, which produced two glass slide portions, each one containing the desired tissue section specimen (TS1 or TS2). Apart from its simplicity, the main advantage of this procedure compared with the laser microdissection protocol, ${ }^{2}$ or other manual microdissection methods, ${ }^{2}$ is that DNA can be retrieved without crossover DNA contamination and with minimal loss of material from the tissue specimens.

The measurement of nuclear DNA was performed with the idea of carrying out tetrameric STR typing by multiplex PCR, which is the preferred method in terms of simplicity and discriminatory power for DNA identification purposes. However, the application of two different methods (hybridisation with a highly repetitive $\alpha$ satellite probe $^{7}$ and targeting the single $A M G X / Y$ gene by real time $\mathrm{PCR}^{8}$ ) revealed the absence of nuclear genomic DNA for microsatellite typing in both tissue sections. We measured the amount of mtDNA and evaluated its degree of degradation by monitoring the real time progress of the PCR amplification of two different fragment sizes ( $113 \mathrm{bp}$ and $287 \mathrm{bp}$ ) within the HVI of the mtDNA control region. ${ }^{8}$ A high degree of mtDNA degradation was found, particularly for the DNA extract isolated from TS2, which revealed more than 500 PCR template copies/ $\mu$ l as monitored with the $113 \mathrm{bp}$ design, but less than 20 PCR template copies/ $\mu \mathrm{l}$ for the amplification of the $287 \mathrm{bp}$ fragment.

\section{"Tissue floaters that contaminate paraffin wax embedded tissue blocks are a common problem in surgical pathology"}

Therefore, we attempted mtDNA sequence analysis by endpoint PCR of short amplicons (around $100 \mathrm{bp}$ ), followed by direct cycle sequencing. ${ }^{6}$ Two different HVI haplotypes were determined from each tissue section. The haplotype of the normal tissue section TS1 (16224C, 16234T, 16311C, 16356C; haplogroup K) was different from that of the tumour tissue section TS2 (16256T, 16270T, 16293G; haplogroup U5ala) at a total of seven nucleotide positions (fig 2). No matches were found when these haplotypes were searched 


\section{Take home messages}

- We investigated whether or not benign and cancerous prostatic tissue in the same presurgical haematoxylin and eosin stained slide belonged to the same person

- Manual slide dissection was used to guarantee independent and high recovery DNA isolation from each tissue section, avoiding carryover and background contamination

- Because of the absence of nuclear DNA, haplotype analysis was carried out on mitochondrial DNA and different low frequency hypervariable region I haplotypes were obtained from each tissue section

- Only the normal tissue section haplotype matched that obtained from the patient's blood sample, supporting the hypothesis of sample mix up during block processing or slide preparation

- Mitochondrial genetic typing is recommended to exclude the possibility of carryover artefacts when low DNA content and high degradation compromise conventional short tandem repeat typing

against a mtDNA database of 549 individuals from Portugal, ${ }_{1}^{14}$ or using the SWGDAM mtDNA population Caucasian data set of 1773 individuals. ${ }^{15}$ The high sequence divergence between these two haplotypes (without signs of heteroplasmic positions) cannot be explained by the phenomenon of mtDNA genetic instability in the tumour tissue section. We concluded that the donor of tissue section TS1 was different from the donor of tissue section TS2. Only the haplotype of the normal tissue section TS1 matched the haplotype obtained from a reference blood sample of the presumptive patient, indicating that the cancer tissue section must have originated from an unknown patient. Therefore, this study supported the hypothesis of a sample mix up by a carryover mechanism. Tissue floaters that contaminate paraffin wax embedded tissue blocks are a common problem in surgical pathology. These fragments of tissue can accidentally be included in paraffin wax blocks if, during gross examination or during embedding, instruments are not properly cleaned between different surgical specimens. In this situation, the foreign tissue appears in all the sections obtained from cutting the paraffin wax block. In our case, odd tissue was found twice among four identical serial sections, so that contamination probably occurred when the sections were picked up on to the glass slide from the flotation bath.

Mitochondrial genetic typing is recommended to exclude the possibility of carryover artefacts when low DNA content and a high degree of degradation compromise conventional STR typing. Fixed tissue sections on microscopic slides should be considered as potential LCN DNA samples and consequently a rigorous protocol to minimise background and crossover DNA contamination should be followed. The use of specific and highly sensitive methods of DNA measurement is also recommended for LCN DNA typing, and should help to decide whether the isolated DNA is suitable for nuclear or mtDNA analysis, and to adjust the DNA input to improve the performance of subsequent endpoint PCR based DNA typing approaches.

\section{Authors' affiliations}

A Alonso, C Albarrán, L Fernández de Simón, P Martín, M Sancho,

Instituto Nacional de Toxicología y Ciencias Forenses, Servicio de Biología, Luis Cabrera 9, 28002 Madrid, Spain

C Alves, L Pereira, L Gusmão, A Amorim, Instituto de Patologia e Imunologia Molecular da Universidade do Porto (IPATIMUP), Rua Dr Roberto Frias, s/n 4200-465 Porto, Portugal

M P Suárez-Mier, Instituto Nacional de Toxicología y Ciencias Forenses, Servicio de Histopatologia, Madrid, Spain

O García, Area de Laboratorio Ertzaintza, Larrauri Mendotxe Bidea 18, 48950, Erandio, Bizkaia, Spain

Correspondence to: Dr A Alonso, Instituto Nacional de Toxicología y Ciencias Forenses, Servicio de Biología, Luis Cabrera 9, 28002 Madrid, Spain; a.alonso@mju.es

Accepted for publication 3 August 2004

\section{REFERENCES}

1 Ramsay AD. Errors in histopathology reporting: detection and avoidance. Histopathology 1999;34:481-90.

2 Hunt JL, Swalsky P, Sasatomi E, et al. A microdissection and molecular genotyping assay to confirm the identity of tissue floaters in paraffinembedded tissue blocks. Arch Pathol Lab Med 2003;127:213-17.

3 Sano K, Takayanagi K, Kaneko T, et al. Application of short tandem repeat of genomic DNA and mitochondrial DNA for identification of mixed-up tissue specimens. Pathol Int 2000;50:1-6.

4 Horn LC, Edelmann J, Hanel C, et al. Identity testing in cervical carcinoma in case of suspected mix-up. Int J Gynecol Pathol 2000;19:387-9.

5 Tsongalis GJ, Berman MM. Application of forensic identity testing in a clinical setting. Specimen identification. Diagn Mol Pathol 1997;6:111-14.

6 Alonso A, Albarrán C, Martín P, et al. Multiplex-PCR of short amplicons for mtDNA sequencing from ancient DNA. In: Brinkmann B, Carracedo A, eds. Progress in forensic genetics, Vol. 9. Amsterdam: Elsevier, 2003:585-8.

7 Walsh PS, Varlaro J, Reynolds R. A rapid chemiluminescent method for quantitation of human DNA. Nucleic Acids Res 1992;20:5061-5.

8 Alonso A, Martín P, Albarrán C, et al. Real-time PCR designs to estimate nuclear and mitochondrial DNA copy number in forensic and ancient DNA studies. Forensic Sci Int 2004;139:141-9.

9 Wilson MR, DiZinno JA, Polanskey D, et al. Validation of mitochondrial DNA sequencing for forensic casework analysis. Int J Legal Med 1995;10:68-74.

10 Alonso A, Albarrán C, Martín P, et al. Mitochondrial DNA sequencing in casework: sequence and length heteroplasmy and other issues of forensic significance. In: Brinkmann B, Carracedo A, eds. Progress in forensic genetics, Vol. 8. Amsterdam: Elsevier, 2000:58-60.

11 Gill P. Application of low copy number DNA profiling. Croat Med J 2001;42:229-32.

12 Budowle B, Hobson D, Smerick J, et al. Low copy number: consideration and caution. Proceedings from the Twelfth International Symposium on Human Identification 2001 (www.promega.com/geneticidproc/ussymp 12proc/ contents/budowle.pdf).

13 Epstein JI, Woino KJ. The prostate and seminal vesicles. In: Sternberg SS, ed. Diagnostic surgical pathology, 3rd ed. Lippincott \& Wilkins, 1999:1893-942.

14 Pereira L, Cunha C, Amorim A. Predicting sampling saturation of mtDNA haplotypes: an application to an enlarged Portuguese database. Int J Legal Med [ln press.]

15 Monson K, Miller K, Wilson M, et al. The mtDNA population database: an integrated software and database resource for forensic comparison. Forensic Science Communications 2002;4 (http://www.fbi.gov/hq/lab/fsc) backissue/april2002/miller1.htm).

16 Anderson S, Bankier AT, Barrell BG, et al. Sequence and organization of the human mitochondrial genome. Nature 1981;290:457-65. 